\title{
Validation of land surface products for modelling the climate impacts of large-scale revegetation in Queensland
}

$\underline{\text { Jianting Chu }^{\mathrm{a}}}$, Jozef Syktus ${ }^{\mathrm{b}}$, Clive McAlpine ${ }^{\mathrm{a}}$, Marcus Thatcher ${ }^{\mathrm{c}}$, Peter Scarth ${ }^{\mathrm{d}}$, Stephen Jeffrey ${ }^{\mathrm{b}}$, Jack Katzfey ${ }^{\mathrm{c}}$, Hong Zhang ${ }^{\mathrm{b}}$, John McGregor ${ }^{\mathrm{c}}$ and Christine Adams-Hosking ${ }^{\mathrm{a}}$

${ }^{a}$ The University of Queensland, School of Geography, Planning and Environmental Management, Brisbane, Australia 4072

${ }^{b}$ Queensland Climate Change Centre of Excellence, Department of Environment and Resource Management, Ecosciences Precinct, 41 Boggo Rd, Dutton Park Qld 4102, Australia

${ }^{c}$ CSIRO Marine and Atmospheric Research, Private Bag 1, Aspendale, VIC 3195, Australia,

${ }^{d}$ Remote Sensing Centre, Department of Natural Resources and Water, Queensland Government, Ecosciences Precinct, 41 Boggo Rd, Dutton Park Qld 4102, Australia

E-mail:j.chu1@uq.edu.au

\begin{abstract}
Global warming is affecting extreme events, such as floods, droughts, heat waves and bushfires, with important consequences for human communities and ecosystems. Large-scale reforestation, especially in the tropics and sub-tropics, has the potential to help mitigate this warming trend and the projected increases in extreme events. This raises an important question for Australia: what is the potential of large-scale reforestation to help mitigate projected changes in climate during the 21st Century? An important first step in addressing this question is to accurately represent key land surface characteristics in a climate model.

We evaluated land use and land cover data currently used in the CSIRO variable resolution Conformal-Cubic Atmospheric Model (CCAM) in preparation for simulating the climate impacts of large-scale reforestation in Queensland. CCAM land-use datasets are based on Boston University MODIS Collection 4 LAI and the IGBP (International Geosphere-Biosphere Programme) land use classification datasets. These datasets were adapted for use with the CSIRO Atmosphere Biosphere Land Exchange (CABLE) land surface model that is coupled to CCAM.
\end{abstract}

New land use datasets for Australia recently became available which capture land use changes more accurately than the existing datasets used in CCAM. This paper describes an updated land-use dataset for running the CABLE model within CCAM to represent land use and land cover conditions in Australia. Analysis shows that the IGBP dataset currently used in CCAM does not incorporate recent land cover and land use changes in eastern Australia. For this reason, we updated the IGBP land cover data set in the Australian region using the National Vegetation Inventory System (NVIS) dataset which includes the current extent of broad vegetation classes for the state and also a more recent cropping data layer.

The LAI (Leaf Area Index) dataset currently used in CCAM was adapted from the Boston University product, with further improvements by CSIRO to derive a prototype monthly LAI dataset. This dataset was based on the MODIS Collection 4 product (2001-2005), which has been shown to have low accuracy in semi-arid regions. This limitation prompted us to evaluate the Community Land Model (CLM) and Beijing Normal University (BNU) LAI products. We found that the BNU LAI performed better than the CCAM or CLM LAI datasets for Queensland. In addition, the BNU dataset is derived from MODIS Collection 5 and captures LAI for the period 2000-2009, thereby providing a longer-term estimation of LAI and was subsequently adopted for use in the CCAM model.

The evaluation of existing land cover, land use and LAI datasets in the CCAM model has identified more recent and improved datasets as being suitable for updating the land cover, land use and LAI in CCAM. The impact of these updated LULC and LAI datasets is currently being evaluated in the CCAM simulations, and the results from this evaluation will be presented at the conference.

Keywords: Land cover, land use, Leaf Area Index, CCAM, Australia 


\section{INTRODUCTION}

Climate change is an urgent global issue, with anthropogenic warming and sea level rise projected to continue for centuries even if greenhouse gas concentrations are stabilised at current levels (IPCC 2007; Steffen 2006; Rahmstorf et al., 2007). There is increasing realization of the difficulty of avoiding dangerous and irreversible climate change. Consequently, it is urgent that all viable options for mitigation and adaptation be explored (Solomon et al., 2009). A recent study by Bala et al. (2007) suggests that reforestation in the tropics and subtropics may be beneficial for the mitigation of global warming as well as providing benefits for carbon sequestration and maintenance of ecological services. Restoring native vegetation at a regional scale has the potential to reduce the impact of climate extremes (Deo et al. 2009). In Australia, the historical clearing of native vegetation has been shown to be an important factor influencing regional climate (McAlpine et al. 2007). McAlpine et al. (2007) showed a significant warming of $0.1-0.6^{\circ} \mathrm{C}$ during summer in eastern Australia over the past 200 years, while the mean summer rainfall showed a significant decrease by $4-12 \%$ in southeast Australia. In addition, the $2002 / 2003 \mathrm{El}$ Niño drought was up to $2^{\circ} \mathrm{C}$ hotter. In a subsequent study using the same experimental design, Deo et al. (2009) found an increase in the frequency of hot and dry days for modern land cover conditions. These changes were especially pronounced during strong El Niño events. Given the impact of historical land clearing on the Australian climate plus its contribution to national greenhouse gas emissions, it is critical to determine to what degree restoring woody native vegetation would contribute to mitigating increases in the severity, frequency and duration of extreme events which are anticipated under a global warming scenario.

We intend to conduct an ensemble of simulations for the period 1970-2085 using the high resolution Cubic Conformal Atmospheric Model (CCAM, see McGregor \& Dix, 2008). These experiments will use boundary conditions from the CSIRO Mark 3.6 global climate model using emission scenarios developed for the 5th Assessment Report of the Intergovernmental Panel on Climate Change. The results from these simulations will be used as a benchmark for assessing the impact of reforestation on Australia's regional climate. We also plan to conduct a series of simulations for the period 2010-2085 using various reforestation scenarios with incremental increases in woody vegetation fraction. The purpose of the latter experiments is to determine a threshold value of reforestation which would result in a statistically significant impact on mean and extreme climate. Queensland provides a suitable case study to begin to address this problem. Recent satellite monitoring indicates that land use and land cover change is still active in Queensland, with the Brigalow Belt the most affected region (Seabrook et al. 2006). The clearance of native vegetation peaked at over 500,000 ha/year between 2000 and 2004, mainly for beef cattle pastures. This ranked the region $5^{\text {th }}$ worldwide on deforestation rate (Lepers et al. 2005). Unlike southeast and southwest Australia, however, the sub-tropical and tropical forests and woodlands of Queensland are able to regenerate naturally through vegetative means (regrowth), hence avoiding the need for expensive manual revegetation programs.

The specific aim of this paper is to describe and evaluate new land cover and vegetation Leaf Area Index (LAI) datasets for input into climate modelling experiments aiming to explore different options for large-scale reforestation in Queensland. The new datasets are used for running the CSIRO Atmosphere Biosphere Land Exchange (CABLE) model used within CCAM, and provide an improved representation of recent land cover conditions in Queensland. The new datasets will be used in a series of climate modelling experiments which are part of an Australian Research Council Linkage project addressing an important but as yet unanswered question: what is the potential impact of restoring native woody vegetation on mitigating changes in regional scale climate extremes? The results of the model simulations will be used to assess the feasibility of implementing reforestation as an effective measure to mitigate the regional impacts of global warming, including climate extremes.

\section{DATA AND METHODS}

\subsection{Experimental Design}

The conceptual framework underpinning this research highlights the synergistic impacts and feedbacks on Australia's regional climate resulting from elevated anthropogenic greenhouse gases, other climate forcings and 
land cover change (see McAlpine et al. 2009 for details). The conversion of native vegetation to crops and pastures has resulted in an increased fraction of available energy at the land surface used for sensible heating which contributes to higher average surface temperatures and more hot days (Deo et al. 2009). A warmer climate results in a drier lower atmosphere and decreased latent heating and regional rainfall. These effects are especially pronounced during drought events associated with El Niño. The experimental design used in this project builds on the understanding of these processes. The initial focus is Queensland, and consists of a series of ensemble experiments evaluating the relative impact of large scale (millions $\mathrm{km}^{2}$ ) reforestation on the Queensland climate.

\subsection{Land cover, land use and LAI data sources}

Accurate land-surface datasets are critical for modelling changes in regional climate such as those resulting from different deforestation scenarios (Lawrence 2004; Thatcher 2008). To allow users to run CABLE with CCAM, a basic prototype land-use dataset was provided based on BU MODIS C4 and USGS datasets. However, this dataset has a number of problems and an improved land-use dataset for CABLE regional climate experiments is required. The land-cover classification currently used in the Conformal-Cubic Atmospheric Model (CCAM) model is based on the United States Geological Survey (USGS) Global Land Cover Characteristics Version 2 database at $1 \mathrm{~km}$ resolution. This dataset uses the International Global Biosphere Program (IGBP) classification and was developed in the mid-1990s (Loveland and Belward 1998). It provides a coarse mapping of global land cover and does not capture the recent changes in land cover in Queensland. For this reason, we conducted a semi-quantitative evaluation alternative land cover datasets, including the National Vegetation Inventory System (NVIS) (Department of Environment and Water Resources 2007), state land cover mapping, and the dynamic land cover mapping developed by Geoscience Australia (http://www.ga.gov.au/ausgeonews/ausgeonews200812/landcover.jsp).

LAI is the projected area of leaves for every unit of horizontal area of ground, which is a critical parameter for modelling the climate impacts of land cover and land use change. At present, the LAI used in CCAM was adopted from the Boston University LAI dataset, with further improvements by CSIRO to obtain the multi-year monthly mean (Thatcher, 2008). However, this dataset is based on the MODIS Collection 4 product, which has been shown to have a low accuracy for semi-arid regions (Hill et al. 2006). It also does not capture the recent clearing of native vegetation. For these reasons, we evaluated the Community Land Model (CLM) (Lawrence and Chase, 2007), and Beijing Normal University (BNU) (Yuan et al. 2011) LAI products. The CLM LAI dataset is used to create new Plant Function Type mapping. The BNU dataset is derived from the latest MODIS Collection 5 product. Its retrieval algorithm aims to reduce the uncertainties derived from cloud, snow and instrument problems, and to make the data more continuous for climate modelling (Table 1).

Table 1: Summary of key properties of the MODIS LAI products.

\begin{tabular}{ll}
\multicolumn{2}{c}{ Data Source } \\
CCAM & MODIS C4 \\
CLM & MODIS C4 \\
BNU & MODIS C5
\end{tabular}

Improvement
Boston University,
CSIRO
Boston University
Beijing Normal
University

\section{Period}

$2001-2005$

$2001-2003$

$2000-2009$

\begin{tabular}{|c|}
\hline $\begin{array}{l}\text { ial } \\
\text { tion }\end{array}$ \\
\hline $4 \mathrm{~km}$ \\
\hline$\sim 5 \mathrm{~km}$ \\
\hline $1 \mathrm{~km}$ \\
\hline
\end{tabular}

Temporal Resolution

monthly mean

monthly mean 8-days

\subsection{Evaluation of LAI data against FPC data}

We evaluated the LAI datasets against Foliage Projective Cover (FPC) data derived from Statewide Landcover and Trees Study (SLATS) for Queensland (http://www.derm.qld.gov.au/slats/). FPC is the percentage of ground area covered by the vertical projection of foliage of woody vegetation above $2 \mathrm{~m}$ in height, and is closely related to the photosynthetic and evaporative potential of a vegetation community. Danaher et al. (1992) found a significant non-linear relationship between field measured woody foliage projective cover (FPC) and long term mean NDVI. The same study also developed an empirical relationship between FPC and tree basal area for 
mature vegetation stands, based on a large number of field sites across a broad range of vegetation communities in Queensland.

LAI and FPC follow an exponent relationship (P. Scarf unpublished data), where:

$$
\mathrm{FPC}=1-\mathrm{e}-\mathrm{G} \Omega \mathrm{L}
$$

where $\mathrm{G}$ is the LAI, $\Omega$ is the mean foliage clumping, and $\mathrm{L}$ is the approximation to the leaf area distribution, which is correlated to leaf angles.

From (1), we can convert the FPC into LAI:

$$
\mathrm{G}=-\ln (1-\mathrm{FPC}) /(\Omega \times \mathrm{L})
$$

$\Omega$ and $\mathrm{L}$ are relatively constant for Australian vegetation, with observational values of $\Omega=0.92$, and $\mathrm{L}=0.4$

In order to minimise the effect of ground-cover vegetation and cloud cover, only 'dry season' remote sensing imagery was selected to retrieve the FPC estimation. FPC data for May - October 2009 was selected for Queensland. We selected LAI for the same corresponding months, and then calculated the monthly average. We calculated the difference between woody LAI and the LAI converted from FPC for the evergreen broadleaf forest, woody savannas and savannas land cover classes. In addition, we calculated area-averaged time series of LAI for whole of Queensland and also southeast Queensland.

\section{RESULTS and DISCUSSION}

\subsection{Land cover, land use data}

For Queensland, we found that the NVIS data better represented the broad scale land cover and land use compared to the IGBP dataset. The IGBP land cover classification map (Figure 1a) showed more savannas in central and western Queensland and more open shrublands in southwest Queensland compared to both the preEuropean and current NVIS datasets (Figure 1b,c). There was more woody savannas in northern and eastern Queensland in the pre-European NVIS classification and also more evergreen broadleaf forest in south-east Queensland (Figure 1b). The post-European NVIS dataset indicated more extensive grasslands in western Queensland (Figure 1c) than the IGBP dataset (Figure 1a) and less evergreen broadleaf forest in southeast Queensland. These differences are due to: improved mapping and classification of the NVIS datasets compared to the outdated IGBP dataset; and the recent clearing in Queensland. The modern day native-non native dataset (Figure 1d) showed extensive cleared areas (approximately 30 million ha) which have either been converted to crops or cattle pastures. Within the cleared area, there is approximately 6 million ha of regrowth native vegetation which was formerly woody savannas or evergreen broadleaf forest. Regrowth is structurally similar to savannas and was reclassified to this vegetation type in Figure 1c.

Our evaluation of existing and more recent land cover and land use datasets highlights the importance of accurately representing land cover conditions when modelling the impact of both deforestation and reforestation on Australia's climate. Discrepancy in the datasets currently used in the CCAM model have important repercussions for the reliability of any modelling experiments which aim to test the impact of land cover change on the region's climate. For this reason, we have replaced the IGBP land cover data set in CCAM with a modified NVIS data set which includes the current extent of broad vegetation classes for the state and also a more recent cropping data layer. The inclusion of the cleared areas, including regrowth vegetation, and the intensive cropping land use, allows the development of realistic scenarios for the quantitative evaluation of the potential contribution of reforestation to help mitigate the impacts of climate change in Queensland. The improved vegetation and land cover mapping for Queensland makes it an ideal initial case study to test this contribution. However, other regions of Australia also have experienced extensive land clearing. We plan to 


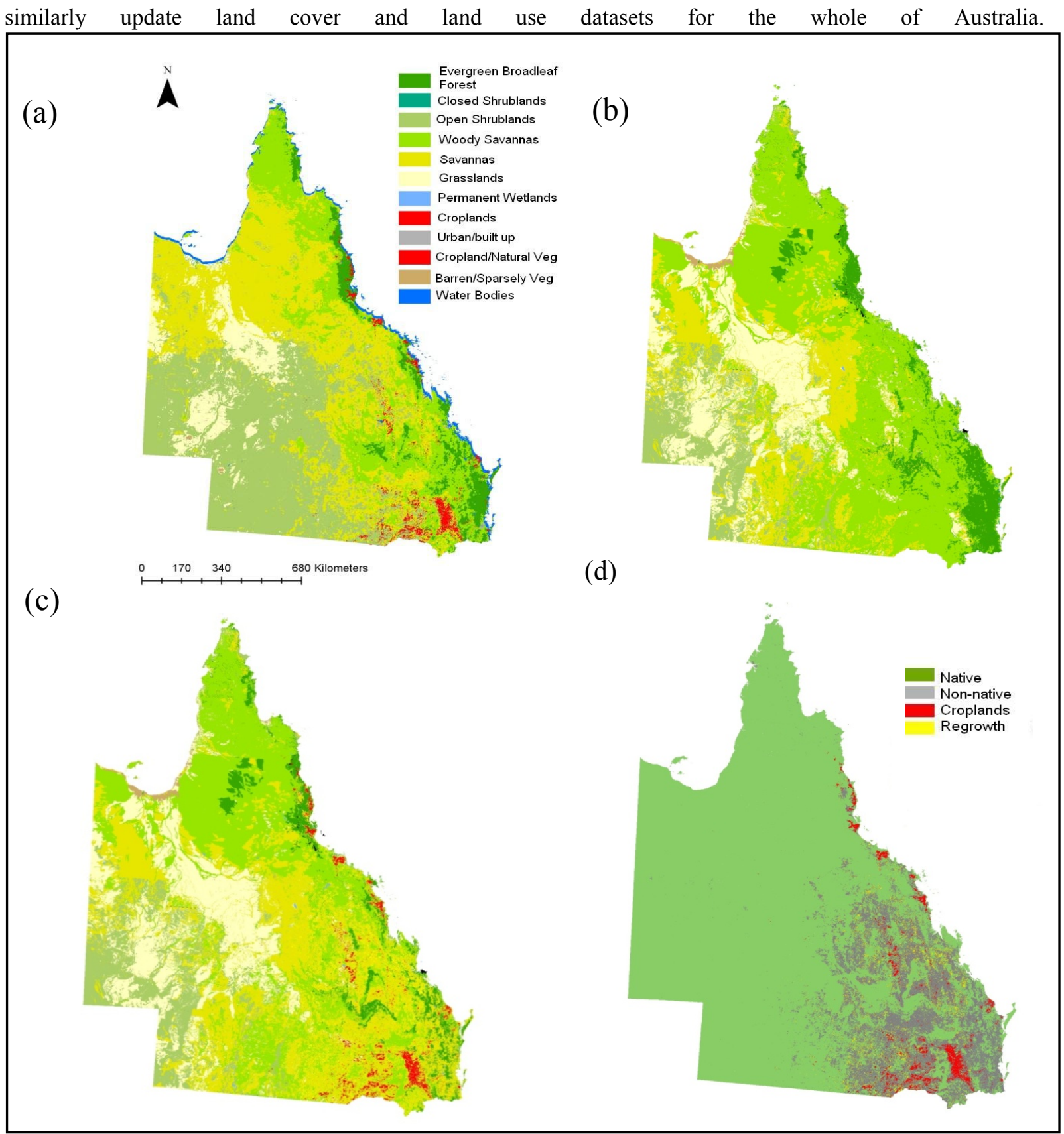

Figure 1. Land cover maps of Queensland, showing: (a) IGBP land cover with $1 \mathrm{~km}$ resolution; (b) NVIS pre-European native vegetation cover with $100 \mathrm{~m}$ resolution; (c) NVIS post-European native vegetation cover with $100 \mathrm{~m}$ resolution and (d) NVIS post-European vegetation cover with $100 \mathrm{~m}$ resolution showing native/non-native land cover, croplands and regrowth/modified native vegetation. Croplands data sourced from ABARE-BRS (2010). NVIS data sourced from DEWR (2007).

\subsection{LAI data}

Overall, for Queensland, we found that the BNU LAI performed better than the CCAM or CLM LAI datasets. The BNU dataset derived from MODIS Collection 5 captures LAI for the period 2000-2009. It provides a longer term estimation of LAI and therefore is better for obtaining climatological values of LAI. The LAI derived from CCAM (Figure 2a) and the CLM (Figure 2b) showed a similar pattern when compared to the LAI values derived from the FPC data. Both datasets tended to overestimate LAI in the coastal evergreen broadleaf forests and the woody savannas of tropical Queensland. In contrast, the BNU data showed a better correspondence in tropical Queensland and in coastal regions, although it also overestimated the values for Evergreen Broadleaf (Figure 2c), with some underestimation of LAI for the woody savannas. For Queensland and south-east 
Chu et al., Validation of land surface products for modelling the climate impacts of large-scale revegetation...

Queensland, the LAI peaked in February and March and was lowest for June to August (Figure 3a). The LAI values were higher for south-east Queensland than for the whole state. There was also strong inter-annual variability in LAI values for the period 2000-2009. This seasonal variability in LAI data is consistent with seasonal cycle of rainfall in Queensland and south-east Queensland. Similar to land use and land cover, LAI is a key dataset in the CCAM climate model. Our evaluation showed that the Boston University LAI product overestimates the LAI of the evergreen broadleaf forests and the woody savannas land cover classes, which represent dense woody native vegetation cover. The CLM LAI product also showed a similar overestimation. These products performed better in the savannas which have sparser tree cover.
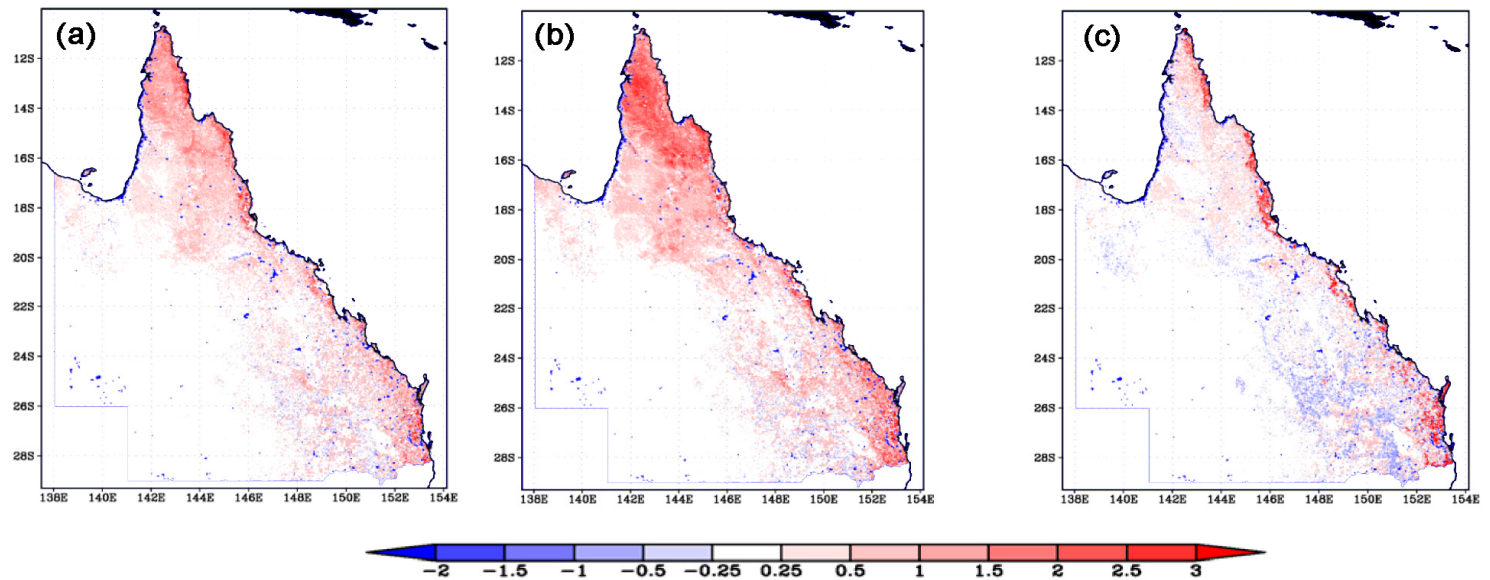

Figure 2. The difference between woody LAI and the LAI values converted from FPC for Queensland in 2009 for: (a) LAI data derived from CCAM, (b) LAI data derived from CLM, and (c) LAI data derived from BNU.
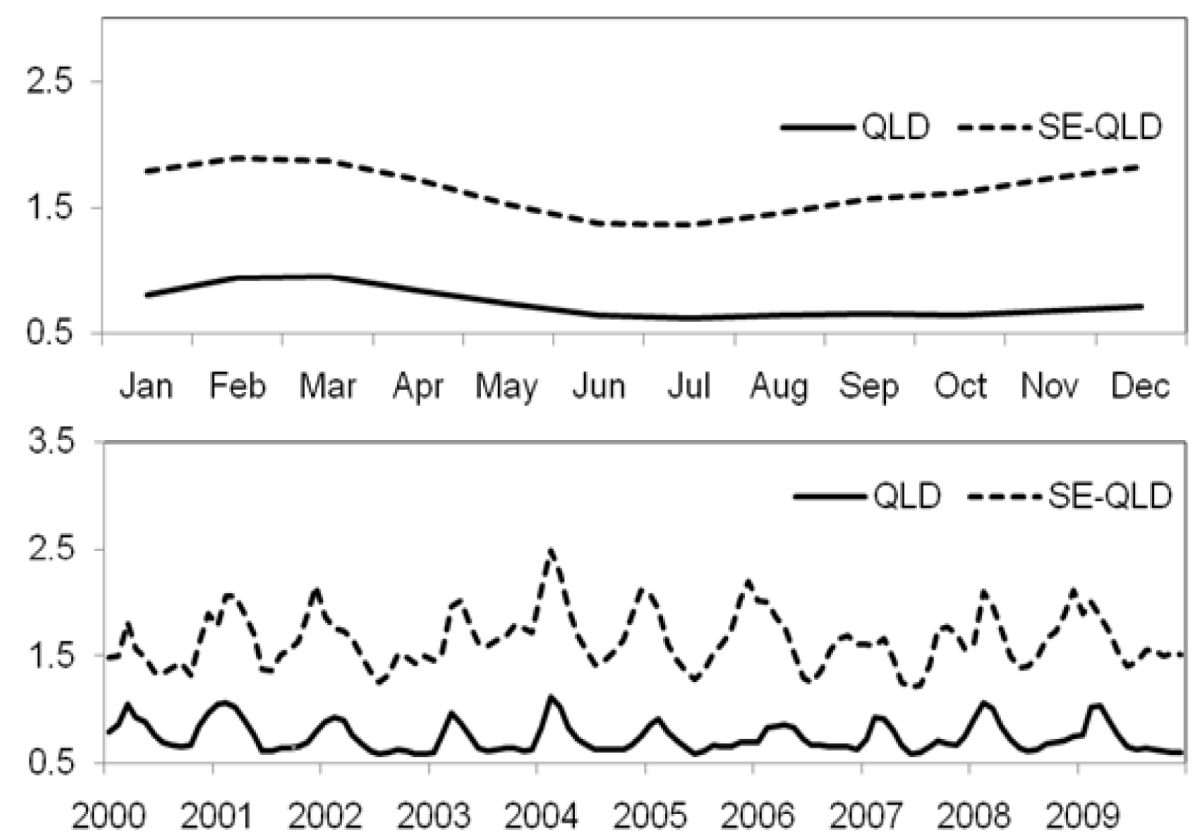

Figure 3. Time series of area average LAI values based on BNU dataset: (a) seasonal cycle and (b) inter-annual for 2000 to 2009 period. Data is for Queensland (QLD) and Southeast Queensland (SE-QLD).

\section{CONCLUSION}

This paper has provided an evaluation of existing land cover, land use and LAI datasets in the CCAM model. It has identified that the more recent datasets as being better capable of representing the land cover, land use and LAI in CCAM. The impact of these updated LULC datasets and LAI datasets in Australia are being evaluated 
Chu et al., Validation of land surface products for modelling the climate impacts of large-scale revegetation...

from the CCAM simulations comparing the new and old datasets. The results of these simulations will be presented at the MODSIM conference.

\section{ACKNOWLEDGEMENTS}

This research was funded by the ARC-Linkage project LP100100738. Hua Yuan, Leonie Seabrook, Richard Thackway, Leo Lymburner, Tim Danaher, Ronglin Tang, Brandy Ream, Lorenzo Cattarino, Fubao Sun provided assistance with providing datasets and analysis.

\section{REFERENCES}

ABARE-BRS (2010). Catchment Scale Land Use Mapping for Australia Update March 2010 (CLUM Update 03/10) dataset, Canberra, ACT, Australia.

Bala, G., K. Caldeira, M. Wickett, T.J. Phillips, D.B. Lobell, C. Delire, and A. Mirin (2007). Combined climate and carbon-cycle effects of large-scale deforestation, PNAS, 104(16), 6550-6555.

Barson, M., L. Randall, and V. Bordas (2000). Land Cover Change in Australia. Report, Bureau of Rural Sciences, Canberra.

Danaher, T.J., J.O. Carter, K.D. Brook, A. Peacock, and G.S. Dudgeon, 1992. Broad-scale vegetation mapping using NOAA-AVHRR imagery, Sixth Australasian Remote Sensing Conference Proceedings, pp.128-137.

Deo, R.C., J.I. Syktus, C.A. McAlpine, P.J. Lawrence, H.A. McGowan, and S.R. Phinn (2009). Impact of historical land cover change on daily indices of climate extremes including droughts in eastern Australia, Geophysical Research Letters, 36, L08705, doi:08710.01029/02009GL037666.

DEWR (2007). Australia's Native Vegetation: A Summary of Australia's Major Vegetation Groups, 2007. Australian Government, Canberra, ACT, Australia.

Hill, M.J., U. Senarath, A. Lee, M. Zeppel, J.M. Nightingale, R.D.J. Williams, and T.R. McVicar (2006). Assessment of the MODIS LAI product for Australian ecosystems, Remote Sensing of Environment, 101, 495-518.

IPCC (2007). Climate Change 2007: The physical science basis. Contribution of Working Group I to the Fourth Assessment Report of the Intergovernmental Panel on Climate Change, 996 pp., Cambridge University Press, Cambridge, United Kingdom and New York, NY, USA.

Lawrence, P.J. (2004), Climate impacts of Australian land cover change. Ph.D. Thesis, UQ, Brisbane, Australia.

Lawrence, P.J., and T.N. Chase (2007). Representing a new MODIS consistent land surface in the Community Land Model (CLM 3.0), Journal of Geophysical Research, 112, G01023, doi:01010.01029/02006JG000168.

Lepers, E., E.F. Lambin, A.C. Janetos, R. DeFries, F. Achard, N. Ramankutty, and R.J. Scholes (2005). A synthesis of rapid land-cover change information for the 1981-2000 period. Bioscience, 55, 115-124.

Loveland, T.R., and A.S. Belward, (1998). The International Geosphere Biosphere Programme Data and Information System Global Land Cover Data Set (DISCover): Acta Astronautica, 41(4 -10), 681-689.

McAlpine, C., J. Syktus, R.C. Deo, P.J. Lawrence, H.A. McGowan, I.G. Watterson, and S.R. Phinn (2007). Modeling the impact of historical land cover change on Australia's regional climate, Geophysical Research Letters, 34, L22711, doi:22710.21029/22007GL031524.

McAlpine, C., J. Syktus, J.G. Ryan, R.C. Deo, G.M. Mckeon, H.A. Mcgowan, and S.R. Phinn (2009). A continent under stress: interactions, feedbacks and risks associated with impact of modified land cover on Australia's climate, Global Change Biology, 15(3), 2206-2223.

McGregor JL, Dix MR (2008). An updated description of the Conformal-Cubic Atmospheric Model. In: Hamilton K., Ohfuchi W. (eds) High Resolution Simulation of the Atmosphere and Ocean, Springer, pp $51-76$

Rahmstorf, S., A. Cazenave, J.A. Church, J.E. Hansen, R.F. Keeling, D.E. Parker, and R.C.J. Somerville (2007). Recent climate observations compared to projections, Science, 3116, 709.

Seabrook, L., C. McAlpine, and R. Fensham (2006). Cattle, crops and clearing: Regional drivers of landscape change in the Brigalow Belt, Queensland, Australia, 1840-2004, Landsc. and Urban Plan., 78, 373-385.

Solomon, S., G.-K. Plattner, R. Knutti, and P. Friedlingstein (2009). Irreversible climate change due to carbon dioxide emissions, PNAS, 106(6), 1704-1709.

Steffen, W. (2006). Stronger Evidence but New Challenges: Climate Change Science 2001-2005 Report., Department of the Environment and Heritage \& Australian Greenhouse Office, Canberra, ACT.

Thatcher, M. (2008), Processing of global land surface datasets for dynamical downscaling with CCAM and TAPM Report, CSIRO Marine and Atmospheric Research, Aspendale, Victoria, Australia.

Yuan, H., Y. Dai, Z. Xiao, D. Ji, and W. Shangguan (2011). Reprocessing the MODIS Leaf Area Index products for land surface and climate modelling, Remote Sensing of Environment, 115(5), 171-1187. 